\title{
Apocrine Breast Carcinoma Histopathological Characteristics
}

\author{
Marta Maksimiuk, Michal Piotr Budzik*, Aleksandra Sobiborowicz and Anna Maria Badowska-Kozakiewicz \\ Department of Biophysics and Human Physiology, Medical University of Warsaw, Poland
}

Submission: May 30, 2019; Published: June 11, 2019

"Correspondence Author: Michal Piotr Budzik, Department of Biophysics and Human Physiology, Medical University of Warsaw Poland, Poland

\begin{abstract}
Introduction: Apocrine carcinoma (AC) is a distinctive and rare type of malignancy, counted to $0.3-4 \%$ of all breast cancer cases. It does not have a particular clinical or radiological feature, although it is characterized by the apocrine morphology, estrogen receptor-negative and androgen receptor-positive profile.

Material and Methods: Studied material came from biopsies, excisional biopsies and modified radical mastectomies. Examined samples were stained with standard methods including hematoxylin and eosin. To determine the immunohistochemical expression of ER, PR and HER2 receptors appropriate antibodies were used.

Results: Among 1,222 patients with breast cancer only 5 of them were diagnosed with apocrine carcinoma (0.4\%). All of them were above 50 years old (51-63, mean: 57). Tumor size varied from $1.4 \mathrm{~cm}$ to $3.8 \mathrm{~cm}$ with a mean size $2.4 \mathrm{~cm}$, while mean size in all 1,222 studied cases counted for $1.9 \mathrm{~cm} .2$ tumors were classified as high-grade (G3), 1 as G2 and 1 as G2. 4 out of 5 tumors did not affect lymph nodes (N0 stage), whereas 1 sample was classified as N2 with 9/19 affected nodes. This observation was consistent with the whole studied group, in which N0 stage made up the largest percentage.
\end{abstract}

Discussion: Presented results suggest that $\mathrm{AC}$ is less frequent in premenopausal patients. AC tends to present as noninvasive without nodal involvement and its biological behavior is less aggressive. Due to the fact that AC is definitely rare type of breast cancer, modern medicine has still limited options to offer for its treatment. Further research needs to be conducted in order to develop target therapies for this carcinoma.

Keywords: Apocrine Breast Carcinoma; Breast Cancer; Estrogen Receptor; Progesterone Receptor; HER2

Abbreviations: AC: Apocrine Carcinoma; BC: Breast Cancer; ER: Estrogen Receptor; PR: Progesterone Receptor; AR: Androgen Receptor; HER2: Human Epidermal Growth Factor Receptor; TNBC: Triple-Negative Breast Cancer; DFS: Disease-Free Survival; OS: Overall Survival; TNAS: Triple Negative Apocrine Carcinoma

\section{Introduction}

According to estimations performed in 2017 by American Cancer Society, breast cancer (BC) was expected to reach $30 \%$ of all new cancers diagnosed among women [1]. Apocrine carcinoma $(\mathrm{AC})$ is one of the rarest types of this malignancy, comprising from $0.3 \%$ to $4 \%$ of all cases [2]. Cells of AC are usually estrogen receptor (ER) negative, progesterone receptor (PR) negative, but in $100 \%$ of cases androgen receptor (AR) positive. This observation leads to extensive interest in possible treatment encompassing androgen antagonists [3]. On the other hand, about $30 \%$ of AC cases are HER2/neu positive, which enables another treatment possibility with monoclonal antibodies targeting this protein. Consequently, 70\% of cases without HER2/neu expression might be proposed as a subtype of triple-negative breast cancer (TNBC). However, this connection may be misleading due to the fact that $\mathrm{AC}$ is characterized by AR positive expression being unparalleled in TNBC $[3,4]$.

\section{Aim of The Study}

The aim of the study was to asses histological grade, tumor size, lymph nodal status and expression of ER, PR and HER2/ neu in apocrine carcinoma of the breast in comparison to other studied types of breast cancer.

\section{Materials and Methods}

The material consisted of 1,122 tissue blocks derived from patients suffering from breast cancer. Analyzed material came from biopsies, excisional biopsies and modified radical mastectomies. Histological and immunohistochemical studies were performed. Apocrine carcinoma was detected in 5 out of 1,122 samples. Analyzed samples were fixed in $10 \%$ buffered formalin phosphate. After 24-hours fixation, materials were dehydrated and then paraffin blocks were cut into $4 \mu \mathrm{m}$ thick sections. Preparations stained with hematoxylin and eosin 


\section{Cancer Therapy \& Oncology International Journal}

were used for defining type of neoplasm according to WHO classification and grading. Immunohistochemical staining was performed for assessing expression of ER, PR and HER2. Evaluation of these markers was performed as follows: ER and PR were categorized as negative - $(0 \%)$, low positive - $(1-$ $10 \%$ ); nuclear staining in $>10 \%$ of tumor cells was considered positive both for ER and PR. HER2 expression was determined using Hercept Test TM DAKO test (Code: K5204).

\section{Result}

5 cases of apocrine carcinoma represented $0.4 \%$ of all 1,122 studied breast cancer samples. All 5 patients were above 50 years old (51-63; mean: 57). 4 out of 5 tumors were detected in the left breast. 2 samples were classified as high grade (G3), 1 as G2 and 1 as G1. Tumor size varied from $1.4 \mathrm{~cm}$ to $3.8 \mathrm{~cm}$ as follows: $1.4 \mathrm{~cm}$ (T1c), $1.7 \mathrm{~cm}$ (T1c), 2 samples - $2.5 \mathrm{~cm}$ (T2), $3.8 \mathrm{~cm}$ (T2). Mean size was $2.4 \mathrm{~cm}$, whereas mean size in all 1122 samples reached $1.9 \mathrm{~cm} .4$ out of 5 studied tumors were classified as non-invasive, without nodal involvement (N0 stage), while 1 was classified as N2 with metastases in 9/19 lymph nodes. This investigation was in consistency with the whole analyzed group, in which N0 comprised the largest percentage. Distant metastases (M) were not assessed. As far as immunohistochemistry is concerned, none of 5 analyzed cases expressed ER or PR. Positive expression of HER2/neu was detected in only 1 sample, which accounted for $20 \%$ of studied AC cases.

\section{Discussion}

Breast cancer is the most common malignancy among women worldwide [5]. ER, PR and HER2/neu are commonly used for diagnosing process and choosing appropriate treatment options for particular types of breast cancer. However, AR detected in $100 \%$ of ACs is an emerging potential target for accurate diagnosis and targeted treatment [6]. AC is specific for the group of postmenopausal women [3,7-9]. This was confirmed in our study, as mean age of all diagnosed women was 57. Given tumor size, all cases were presented in low stage - none of them reached T3 stage. Similar results were obtained by Mills et al. [3] - the majority of tumors were assessed as T1 or T2 making up $90 \%$ of studied cases - and by Seo et al. [7] - all lesions were described in the range between $1.2 \mathrm{~cm}$ to $2.2 \mathrm{~cm}$. As far as nodal involvement is concerned, analyzed tumors were assessed as non-invasive because of presenting in N0 stage in 4 out of 5 cases. Interestingly, the opposite results were achieved by Liu et al. [6] - they described molecular apocrine breast cancer with tendency to affect more lymph nodes than other studied types of BC. Moreover, they detected a close association between lymph node invasion of $\mathrm{AC}$ and expression of gross cystic disease fluid protein 15 (GCDFP15). This molecule is regulated by AR and was proposed as a negative marker for AC patient's outcome due to significant correlation with shorter disease-free survival (DFS) and overall survival (OS).

Some studies describe AC without Her2 expression as triple-negative apocrine carcinoma (TNAC) [9]. In our study only 1 sample presented Her2 positive expression. In the study conducted by Meattini et al. [9] TNAC were characterized by lower Ki67 index and better survival in comparison to group of non-apocrine triple negative tumors. Their multivariate analysis demonstrated that the only significant factor for OS was the histology of TNAC. On the other hand, Vranic et al. [10] highlighted the necessity of considering apocrine breast cancers as molecularly diverse group and distinguishing pure apocrine carcinomas and apocrine-like carcinomas. According to their study, pure apocrine carcinomas predominantly belong to either HER2 overexpressing or TNBC groups, whereas apocrine-like carcinomas to luminal phenotype.

Numerous studies have proved the prognostic potential of AR expression in $\mathrm{BC}$ and its association with more favorable prognosis. Moreover, several experiments discovered crosstalk between AR and ER by inhibiting each other's activity [11]. Due to emerging role of $\mathrm{AR}$ in BCs, new therapies are consequently implemented. One of them encompasses bicalutamide - a nonsteroidal antiandrogen originally used in the treatment of prostate cancer [12]. The study conducted by Huang et al. [13] revealed the mechanism responsible for effective treatment with bicalutamide usage. This nonsteroidal antiandrogen was proved to block androgen-stimulated oncogenic AR and Wnt/ $\beta$ catenin signaling and as an effect to inhibit the growth of $\mathrm{AR}+/$ ER- breast cancer.

\section{Conclusion}

$\mathrm{AC}$ is a distinctive and rare type of breast cancer. It has tendency to affect older population of females. Although tumors were diagnosed in larger than group average size, they tended to present without nodal involvement. Slightly different results concerning characteristics of $\mathrm{BC}$ subgroup might be explained by small groups incorporated into different analysis. Owing to AR positive expression, new therapies are developed for more specific treatment, however further research is still needed to develop target therapies for this malignancy.

\section{References}

1. Siegel RL, Miller KD, Jemal A. (2017) Cancer Statistics. CA Cancer J Clin 67(1): 7-30.

2. Sekal M, Znati K, Harmouch T, Riffi AA (2014) Apocrine carcinoma of the male breast: a case report of an exceptional tumor. Pan Afr Med J 17(19): 294.

3. Mills AM, C EG, S MW, C MB, Atkins KA (2016) Pure Apocrine Carcinomas Represent a Clinicopathologically Distinct Androgen Receptor-Positive Subset of Triple-Negative Breast Cancers. Am J Surg Pathol. 40(8): 1109-1116.

4. Vranic S, Feldman R, Gatalica Z (2017) Apocrine carcinoma of the breast: A brief update on the molecular features and targetable biomarkers. Bosn J Basic Med Sci 17(1): 9-11.

5. Allemani C, Matsuda T, Di Carlo V, Harewood R, Matz M, Niksic M, et al. (2018) Global surveillance of trends in cancer survival 2000-14 (CONCORD-3): analysis of individual records for 37513025 patients diagnosed with one of 18 cancers from 322 population-based registries in 71 countries. Lancet 391(10125): 1023-1075.

6. Liu X, Feng C, Liu J, Zhao L, Liu J, Zhang W, et al. (2016) Heat shock 


\section{Cancer Therapy \& Oncology International Journal}

protein 27 and gross cystic disease fluid protein 15 play critical roles in molecular apocrine breast cancer. Tumour Biol 37(6): 8027-8036.

7. Seo KJ, An YY, Whang IY, Chang ED, Kang BJ, Kim SH, et al. (2015) Sonography of Invasive Apocrine Carcinoma of the Breast in Five Cases. Korean J Radiol 16(5): 1006-1011.

8. Dalin MG, Desrichard A, Katabi N, Makarov V, Walsh LA, et al (2016) Comprehensive Molecular Characterization of Salivary Duct Carcinoma Reveals Actionable Targets and Similarity to Apocrine Breast Cancer. Clin Cancer Res 22(18): 4623-4633.

9. Meattini I, Pezzulla D, Saieva C, Bernini M, Orzalesi L, Sanchez LJ, et al. (2018) Triple Negative Apocrine Carcinomas as a Distinct Subtype of Triple Negative Breast Cancer: A Case-control Study. Clin Breast Cancer 18(5): 773-780.
10. Vranic S, Tawfik 0, Palazzo J, Bilalovic N, Eyzaguirre E, et al. (2010) EGFR and HER-2/neu expression in invasive apocrine carcinoma of the breast. Mod Pathol 23(5): 644-653.

11. Fioretti FM, Sita-Lumsden A, Bevan CL, Brooke GN (2014) Revising the role of the androgen receptor in breast cancer. J Mol Endocrinol 52(3): 257-265.

12. Arce Salinas C, Riesco Martinez MC, Hanna W, Bedard P, Warner E (2016) Complete Response of Metastatic Androgen Receptor-Positive Breast Cancer to Bicalutamide: Case Report and Review of the Literature. J Clin Oncol 34(4): 21-24.

13. Huang R, Han J, Liang X, Sun S, Jiang Y, Xia B, et al. (2017) Androgen Receptor Expression and Bicalutamide Antagonize Androgen Receptor Inhibit Beta-Catenin Transcription Complex in Estrogen Receptor-Negative Breast Cancer. Cell Physiol Biochem 43(6): 2212-2225.

\section{Your next submission with Juniper Publishers will reach you the below assets}

- Quality Editorial service

- Swift Peer Review

- Reprints availability

- E-prints Service

- Manuscript Podcast for convenient understanding

- Global attainment for your research

- Manuscript accessibility in different formats

( Pdf, E-pub, Full Text, Audio)

- Unceasing customer service

Track the below URL for one-step submission https://juniperpublishers.com/online-submission.php 